\title{
Vacuum-assisted venous return reduces blood usage
}

Michael K. Banbury, MD

Jennifer A. White, MS ${ }^{b}$

Eugene $\mathrm{H}$. Blackstone, $\mathrm{MD}^{\mathrm{a}, \mathrm{b}}$

Delos M. Cosgrove III, MD

From the Departments of Thoracic and Cardiovascular Surgery ${ }^{\mathrm{a}}$ and Biostatistics and Epidemiology, ${ }^{\mathrm{b}}$ The Cleveland Clinic Foundation, Cleveland, Ohio.

Baxter Healthcare provided funding to support medical record review and data collection.

Received for publication Dec 21, 2000; revisions requested Feb 15, 2001; revisions received Sept 4, 2002; accepted for publication Oct 25, 2002.

Address for reprints: Michael K. Banbury, MD, The Cleveland Clinic Foundation, Department of Thoracic and Cardiovascular Surgery, 9500 Euclid Avenue/Desk F25, Cleveland, OH 44195 (E-mail: banburm@ ccf.org).

J Thorac Cardiovasc Surg 2003;126:680-7

Copyright $\odot 2003$ by The American Association for Thoracic Surgery

$0022-5223 / 2003 \$ 30.00+0$

doi:10.1016/S0022-5223(03)00048-5
Objective: To determine whether vacuum-assisted venous return has clinical advantages over conventional gravity drainage apart from allowing the use of smaller cannulas and shorter tubing.

Methods: A total of 150 valve operations were performed at our institution between February and July 1999 using vacuum-assisted venous return with small venous cannulas connected to short tubing. These were compared with (1) 83 valve operations performed between April 1997 and January 1998 using the initial version of vacuum-assisted venous return, and (2) 124 valve operations performed between January and April of 1997 using conventional gravity drainage. Priming volume, hematocrit value, red blood cell usage, and total blood product usage were compared multivariably. These comparisons were covariate and propensity adjusted for dissimilarities between the groups and confirmed by propensity-matched pairs analysis.

Results: Priming volume was $1.4 \pm 0.4 \mathrm{~L}$ for small-cannula vacuum-assisted venous return, $1.7 \pm 0.4 \mathrm{~L}$ for initial vacuum-assisted venous return, and $2.0 \pm 0.4 \mathrm{~L}$ for gravity drainage $(P<.0001)$. Smaller priming resulted in higher hematocrit values both at the beginning of cardiopulmonary bypass $(27 \% \pm 5 \%$ compared with $26 \%$ $\pm 4 \%$ and $25 \% \pm 4 \%$, respectively, $P<.0001)$ and at the end $(30 \% \pm 4 \%$ compared with $28 \% \pm 4 \%$ and $27 \% \pm 4 \%$, respectively, $P<.0001)$. Red cell transfusions were used in $17 \%$ of the patients having small-cannula vacuum-assisted venous return, $27 \%$ of the initial patients having vacuum-assisted venous return, and $37 \%$ of the patients having gravity drainage $(P=.001)$; total blood product usage was $19 \%, 27 \%$, and $39 \%$, respectively $(P=.002)$. Although ministernotomy also was associated with reduced blood product usage $(P<.004)$, propensity matching on type of sternotomy confirmed the association of vacuum-assisted venous return with lowered blood product usage.

Conclusions: Vacuum-assisted venous return results in (1) higher hematocrit values during cardiopulmonary bypass and (2) decreased red cell and total blood product usage.

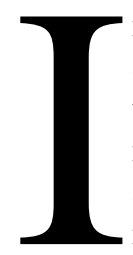

n April of 1997, vacuum-assisted venous return (VAVR) was introduced as a technical improvement to facilitate use of smaller venous cannulas. With the emergence of minimally invasive surgery, smaller cannulas became necessary to reduce interference with exposure in small incisions. As the advantages of VAVR became evident, its application was broadened to include all cardiac surgery requiring cardiopulmonary bypass (CPB).

Because VAVR was introduced as a technical modification of conventional CPB, no randomized protocol was used. To assess the possible clinical benefit accompanying this technical benefit of surgical flexibility, we compared blood product usage in patients undergoing cardiac surgery with short-tubing VAVR, conventionaltubing VAVR, and conventional gravity drainage. 
TABLE 1. Patient and procedure variables (categorical)

\begin{tabular}{|c|c|c|c|c|c|c|c|}
\hline \multirow[b]{3}{*}{ Variable } & \multirow{2}{*}{\multicolumn{2}{|c|}{ Gravity group $(n=124)$}} & \multicolumn{4}{|c|}{ VAVR } & \multirow[b]{3}{*}{$P^{*}$} \\
\hline & & & \multicolumn{2}{|c|}{ Group 1 (n = 83) } & \multicolumn{2}{|c|}{ Group $2(n=150)$} & \\
\hline & $\mathbf{n}$ & $\%$ & $\mathbf{n}$ & $\%$ & $\mathbf{n}$ & $\%$ & \\
\hline Male & 89 & 72 & 51 & 61 & 103 & 67 & .3 \\
\hline $\begin{array}{l}\text { Previous cardiac surgery } \\
\text { Incision }\end{array}$ & 22 & 18 & 14 & 17 & 7 & 5 & $\begin{array}{l}.001 \\
.001\end{array}$ \\
\hline Full sternotomy & 58 & 47 & 18 & 22 & 44 & 29 & \\
\hline Ministernotomy & 45 & 36 & 64 & 77 & 105 & 70 & \\
\hline Thoracotomy & 21 & 17 & 1 & 1 & 0 & 0 & \\
\hline \multicolumn{8}{|l|}{ Aortic valve } \\
\hline Replacement & 47 & 38 & 24 & 29 & 40 & 27 & .1 \\
\hline Repair & 8 & 6 & 3 & 4 & 5 & 3 & .4 \\
\hline \multicolumn{8}{|l|}{ Mitral valve } \\
\hline Replacement & 20 & 16 & 15 & 18 & 12 & 8 & .04 \\
\hline Repair & 39 & 31 & 39 & 47 & 80 & 53 & .001 \\
\hline $\begin{array}{l}\text { Combined aortic and } \\
\text { mitral procedures }\end{array}$ & 1 & 1 & 0 & 0 & 11 & 7 & \\
\hline \multicolumn{8}{|l|}{ Surgeont } \\
\hline D.M.C. & 72 & 58 & 83 & 100 & 101 & 67 & .001 \\
\hline
\end{tabular}

VAVR, Vacuum-assisted venous return.

*Obtained from $\chi^{2}$ test.

tRemaining operations are spread among 10 other surgeons.

\section{Patients and Methods \\ Patients}

A new system for VAVR, using a sealed hard-shell venous reservoir (HSR-4000 gold, Baxter Healthcare, Irvine, Calif) connected to a vacuum regulator, was introduced at The Cleveland Clinic Foundation in 1997. With this system, reservoir pressure can be set at -40 to $-60 \mathrm{~cm} \mathrm{H}_{2} \mathrm{O}$ and adjusted as necessary.

This study was designed to assess the group of patients undergoing valve surgery for whom VAVR modified to minimize tubing volume was used and to compare it with a group in which conventional tubing VAVR was used and another group in which conventional gravity drainage was used. Composition of the 3 study groups is described below.

VAVR group 1. This group consisted of 83 patients undergoing valve operations between April 1997 and January 1998 by one surgeon (D.M.C.). This is the initial group in which VAVR with small venous cannulas and conventional length venous tubing was used. Priming volume was reduced by draining the venous lines.

VAVR group 2. This group consisted of 150 patients undergoing valve operations between February and July of 1999. This is the group in which VAVR with important reduction of tubing length was used. A total of 20.4 feet of tubing was removed from the bypass circuit.

Gravity return group. This group consisted of 124 patients undergoing valve operations between January and April of 1997. This is the group in which conventional gravity drainage was used.

Patients undergoing emergency operations, receiving preoperative hemodialysis or port-access procedures, or having operations involving repair or replacement of an aortic aneurysm were excluded. Patient and procedure characteristics of the 3 study groups are compared in Tables 1 and 2.

\section{Data collection and manipulation}

Funding was provided by Baxter Healthcare (Irvine, Calif) to support medical record review and data collection; however, the firm did not participate in data analysis or manuscript preparation.

Patient history and preoperative, intraoperative, intensive care unit (ICU), and postoperative data were assembled from medical records. Use of the data assembled in routine patient care was approved by The Cleveland Clinic Foundation's Institutional Review Board. Hematocrit data were extracted from the medical records at 4 time points: preoperatively, shortly after CPB was initiated (first bypass), at aortic clamp removal (first postclamp), and at admission to the intensive care unit (first ICU). The following formulas were used to predict patient blood volume and red blood cell volume, using sex, height $(\mathrm{m})$, weight $(\mathrm{kg})$, and hematocrit value $(\%):^{1}$

Men: Blood volume $(\mathrm{L})=0.3669 \cdot$ height $^{3}+0.03219 \cdot$ weight +0.6041

Women: Blood volume $(\mathrm{L})=0.3561 \cdot$ height $^{3}+0.03308 \cdot$ weight +0.1833

Either: Red cell volume $(\mathrm{L})=$ blood volume $\cdot$ hematocrit/100.

The first red cell volume (RCV) on CPB and the first RCV in the ICU were adjusted for priming volume as follows:

$$
\mathrm{RCV}=(\text { Priming volume }+ \text { blood volume }) \cdot \text { hematocrit/100. }
$$

\section{Data Analysis \\ End Points}

End points for the study were (1) total units of packed red blood cells and (2) total units of banked blood products administered intraoperatively and postoperatively. The general policy for transfusion of packed red blood cells was a hematocrit value of $21 \%$ or 
TABLE 2. Patient and procedure variables (continuously distributed)

\begin{tabular}{|c|c|c|c|c|}
\hline \multirow[b]{2}{*}{ Variable } & \multirow[b]{2}{*}{$\begin{array}{c}\text { Gravity group }(n=124) \\
\text { Mean } \pm S D\end{array}$} & \multicolumn{2}{|c|}{ VAVR } & \multirow[b]{2}{*}{$P *$} \\
\hline & & $\begin{array}{l}\text { Group } 1(n=83) \\
\text { Mean } \pm \text { SD }\end{array}$ & $\begin{array}{c}\text { Group } 2(n=150) \\
\text { Mean } \pm S D\end{array}$ & \\
\hline \multicolumn{5}{|l|}{ Demographics } \\
\hline Age (y) & $57 \pm 14$ & $58 \pm 14$ & $58 \pm 14$ & .8 \\
\hline Body surface area $\left(\mathrm{m}^{2}\right)$ & $2 \pm 0.3$ & $2 \pm 0.2$ & $2 \pm 0.2$ & .4 \\
\hline Preoperative hematocrit value (\%) & $36 \pm 5$ & $37 \pm 4$ & $36 \pm 5$ & .8 \\
\hline Blood volume (L) & $5 \pm 1$ & $5 \pm 0.9$ & $5 \pm 0.9$ & .2 \\
\hline Red cell volume (L) & $2 \pm 0.5$ & $1.8 \pm 0.4$ & $1.8 \pm 0.5$ & .5 \\
\hline \multicolumn{5}{|l|}{ Operative } \\
\hline Priming volume $(\mathrm{L})$ & $2.0 \pm 0.4$ & $1.7 \pm 0.4$ & $1.4 \pm 0.4$ & $<.0001$ \\
\hline Hematocrit value (\%): first bypass & $25 \pm 4$ & $26.3 \pm 4$ & $27 \pm 4.8$ & .0002 \\
\hline Red cell volume (L): first bypass & $1.8 \pm 0.5$ & $1.7 \pm 0.4$ & $1.7 \pm 0.5$ & .5 \\
\hline Hematocrit (\%): first postclamp & $27 \pm 4$ & $28 \pm 8.8$ & $30 \pm 4$ & $<.0001$ \\
\hline Red cell volume (L): first postclamp & $2 \pm 0.5$ & $1.8 \pm 0.4$ & $1.9 \pm 0.5$ & .2 \\
\hline Bypass time (min) & $90 \pm 37$ & $70 \pm 20$ & $74 \pm 24$ & $<.0001$ \\
\hline \multicolumn{5}{|l|}{ ICU } \\
\hline Hematocrit value (\%): first ICU & $32 \pm 4$ & $32 \pm 4$ & $32 \pm 4$ & .9 \\
\hline Red cell volume (L): ICU & $1.6 \pm 0.5$ & $1.6 \pm 0.4$ & $1.6 \pm 0.4$ & .5 \\
\hline
\end{tabular}

$I C U$, Intensive care unit; $S D$, standard deviation; VAVR, vacuum-assisted venous return.

*Obtained from Wilcoxon test.

less, consistent with the National Institutes of Health Consensus Conference on Perioperative Red Blood Cell Transfusion. ${ }^{2}$ This policy was consistent across all 3 groups.

\section{Analytic Strategy}

The null hypothesis tested was that there was no difference in packed red cell or total blood product usage (packed red cells, fresh frozen plasma, platelets, or cryoprecipitate) between patients undergoing VAVR and those undergoing conventional gravity drainage. Because the number of units of blood products administered per patient was distributed more "categorically" than continuously, the end points were dichotomized (use or not of blood products) and multivariable logistic regression performed. ${ }^{3}$ The objective of the analyses was to detect differences in these end points among 3 groups of patients; therefore, a variable representing VAVR group 1 and VAVR group 2 was forced into each model as the initial step. Then, adjusting covariates were sought from patient and procedure variables (Appendix 1) using a guided stepwise approach. ${ }^{4}$ The $P$ value criterion used to retain variables in the analyses was .05.

Because the study was not randomized, baseline differences existed among the 3 patient groups (Tables 1 and 2). These differences were quantified by multivariable logistic regression (Appendix Table 1), the results of which were considered in developing propensity models, one for the probability of receiving VAVR 1 and the other VAVR 2. ${ }^{5,6}$ Appendix 2 contains details on the conditional probability computations needed for this, based on methods described by Hosmer and Lemeshow. ${ }^{3}$ The 2 propensity scores were used to further adjust the multivariable comparisons of groups.

\section{Specific Methods}

Logistic regression models were constructed for red blood cell usage and for total blood product usage. Variables considered for adjustment included demographic and preoperative hematologic measures, cardiac and noncardiac comorbidity, and operative procedures (Appendix 1). Interactions between group and surgical variables were investigated.

Because of confounding between blood product usage and increasing use of minimally invasive incisions across the time frame of the study, the overall results were confirmed in two groups of patients that were pairwise propensity matched for full sternotomy versus minimally invasive approach (Appendix 2).

\section{Results}

\section{Influence of VAVR}

Compared with gravity drainage, both initial VAVR (group 1 ), in which venous lines were drained, and VAVR with short tubing (group 2) resulted in incrementally lower priming volume and higher hematocrit values during CPB (Table 2).

\section{Use of Blood Products}

Red blood cell transfusions were given to 94 patients, and 99 patients received some form of blood product intraoperatively or postoperatively (Table 3 ). Packed red blood cells were used in $37 \%$ of the gravity drainage group, $27 \%$ of VAVR group 1, and $17 \%$ of VAVR group 2. After adjusting for age, blood volume, full sternotomy, mitral valve repair, and propensity scores, the probability of receiving red blood cells was 55\% lower in VAVR group 1 and $88 \%$ lower in VAVR group 2 than in the gravity drainage group (Table 4). The same relations held for total blood product usage (Tables 3 and 5).

Blood products were used more frequently in elderly patients, those with lower blood volume, and those under- 


\begin{tabular}{|c|c|c|c|c|c|c|c|}
\hline \multirow[b]{3}{*}{ Variable } & & & \multicolumn{4}{|c|}{ VAVR } & \multirow[b]{3}{*}{$P^{*}$} \\
\hline & \multicolumn{2}{|c|}{ Gravity group $(n=124)$} & \multicolumn{2}{|c|}{ Group $1(n=83)$} & \multicolumn{2}{|c|}{ Group $2(n=150)$} & \\
\hline & $\mathbf{n}$ & $\%$ & $\mathbf{n}$ & $\%$ & $\mathbf{n}$ & $\%$ & \\
\hline Intraoperative RBCs used & 31 & 25 & 9 & 11 & 19 & 13 & .007 \\
\hline Postoperative RBCs used & 23 & 18 & 16 & 19 & 16 & 11 & .1 \\
\hline RBCs used intraop or postop & 46 & 37 & 22 & 27 & 26 & 17 & .001 \\
\hline Blood products used intraop or postop & 48 & 39 & 22 & 27 & 29 & 19 & .002 \\
\hline
\end{tabular}

VAVR, Vacuum-assisted venous return; $R B C s$, red blood cells.

*Obtained from $\chi^{2}$ test.

TABLE 4. Probability of receiving packed red blood cells intraoperatively or postoperatively (multivariable logistic regression)

\begin{tabular}{|c|c|c|c|c|}
\hline \multirow[b]{2}{*}{ Variable } & \multicolumn{2}{|c|}{ Without propensity adjustment } & \multicolumn{2}{|c|}{ With propensity adjustment } \\
\hline & Coefficient \pm SD & $\boldsymbol{P}$ & Coefficient \pm SD & $\boldsymbol{P}$ \\
\hline \multicolumn{5}{|l|}{ Demographics } \\
\hline Age (y) & $0.042 \pm 0.011$ & .0001 & $0.039 \pm 0.011$ & .0005 \\
\hline Blood volume $(\mathrm{L})^{*}$ & $-0.97 \pm 0.171$ & $<.0001$ & $-0.96 \pm 0.178$ & $<.0001$ \\
\hline \multicolumn{5}{|l|}{ Procedure } \\
\hline Full sternotomy & $0.87 \pm 0.316$ & .006 & $1.35 \pm 0.439$ & .002 \\
\hline Mitral valve repair* & $-0.90 \pm 0.342$ & .008 & $-0.98 \pm 0.351$ & .005 \\
\hline \multicolumn{5}{|l|}{ Group } \\
\hline VAVR group $1^{*}$ & $-0.58 \pm 0.387$ & .1 & $-0.79 \pm 0.427$ & .06 \\
\hline VAVR group $2^{*}$ & $-1.19 \pm 0.345$ & .0006 & $-1.49 \pm 0.395$ & .0001 \\
\hline \multicolumn{5}{|l|}{ Propensity } \\
\hline $\begin{array}{l}\text { Probability VAVR } \\
\text { group } 1\end{array}$ & - & - & $0.15 \pm 0.180$ & .4 \\
\hline $\begin{array}{l}\text { Probability VAVR } \\
\text { group } 2\end{array}$ & - & - & $0.38 \pm 0.228$ & .09 \\
\hline Intercept & $1.65 \pm 1.09$ & & $2.23 \pm 1.147$ & \\
\hline
\end{tabular}

$S D$, Standard deviation; VAVR, vacuum-assisted venous return.

*Negative coefficient indicates decreased probability of packed red blood cell usage.

going full sternotomy. They were used less often in patients having mitral valve repair (Tables 4 and 5).

\section{Confirmation}

Among the propensity-matched pairs of patients for full sternotomy versus minimally invasive incisions, the probability of receiving any blood product was no longer associated with either surgical approach or mitral valve repair (Table 6). However, its association with age, blood volume, and, most important, VAVR was entirely consistent with the findings of the main analysis.

\section{Discussion}

\section{Principal Findings}

VAVR dates to the earliest days of cardiac surgery, ${ }^{7,8}$ but interest has been rekindled by a new enthusiasm for minimally invasive surgery. As expected from both drainage of venous lines and subsequent shortening of all tubing within the cardiopulmonary bypass circuit, VAVR allowed a no- tably lower priming volume. Lower priming volume resulted in higher on-pump hematocrit values, and this was associated with a reduced number of patients requiring transfusion. Low priming volume has been shown by Jansen and colleagues ${ }^{9}$ to reduce both post-CPB hyperdynamic response and use of banked blood. Low prime circuits have also been linked to shortened intubation and recovery times. ${ }^{10,11}$

These findings are at odds with the principle of normovolemic hemodilution. However, in 3 separate studies, Höhn, ${ }^{12}$ Casati, ${ }^{13}$ Weiskopf, ${ }^{14}$ and their colleagues found a lack of efficacy of normovolemic hemodilution in reducing transfusion requirements in cardiac surgery.

In addition to reducing priming volume, another hypothesis for the clinical benefit of VAVR is the noticeably drier operative field. This reduces the amount of blood exposed to damaging effects of pump suction and basket suction salvage. It may also reduce the amount scavenged by wall 
TABLE 5. Probability of receiving any blood products intraoperatively or postoperatively (multivariable logistic regression)

\begin{tabular}{|c|c|c|c|c|}
\hline \multirow[b]{2}{*}{ Variable } & \multicolumn{2}{|c|}{ Without propensity adjustment } & \multicolumn{2}{|c|}{ With propensity adjustment } \\
\hline & Coefficient \pm SD & $\boldsymbol{P}$ & Coefficient \pm SD & $P$ \\
\hline \multicolumn{5}{|l|}{ Demographics } \\
\hline Age (y) & $0.039 \pm 0.0106$ & .0002 & $0.036 \pm 0.010$ & .0007 \\
\hline Blood volume (L)* & $-0.86 \pm 0.162$ & $<.0001$ & $-0.86 \pm 0.169$ & $<.0001$ \\
\hline \multicolumn{5}{|l|}{ Procedure } \\
\hline Full sternotomy & $0.74 \pm 0.305$ & .02 & $1.23 \pm 0.422$ & .004 \\
\hline Mitral valve repair* & $-0.90 \pm 0.327$ & .006 & $-0.98 \pm 0.351$ & .005 \\
\hline \multicolumn{5}{|l|}{ Group } \\
\hline VAVR group $1^{*}$ & $-0.65 \pm 0.376$ & .08 & $-0.88 \pm 0.416$ & .03 \\
\hline VAVR group $2^{*}$ & $-1.08 \pm 0.330$ & .001 & $-1.40 \pm 0.380$ & .0002 \\
\hline \multicolumn{5}{|l|}{ Propensity } \\
\hline Probability VAVR group 1 & - & - & $0.14 \pm 0.173$ & .4 \\
\hline Probability VAVR group 2 & - & - & $0.38 \pm 0.218$ & .08 \\
\hline Intercept & $1.44 \pm 1.05$ & & $2.02 \pm 1.105$ & \\
\hline
\end{tabular}

$S D$, Standard deviation; VAVR, vacuum-assisted venous return.

*Negative coefficient indicates decreased probability of blood product usage.

TABLE 6. Probability of receiving any blood products intraoperatively or postoperatively in propensity-matched pairs of patients for surgical approach (multivariable logistic repression)

\begin{tabular}{|c|c|c|c|c|}
\hline \multirow[b]{2}{*}{ Variable } & \multicolumn{2}{|c|}{ Without propensity adjustment } & \multicolumn{2}{|c|}{ With propensity adjustment } \\
\hline & Coefficient \pm SD & $\boldsymbol{P}$ & Coefficient \pm SD & $\boldsymbol{P}$ \\
\hline \multicolumn{5}{|l|}{ Demographics } \\
\hline Age $(y)$ & $0.056 \pm 0.014$ & $<.001$ & $0.050 \pm 0.016$ & .002 \\
\hline Blood volume $(\mathrm{L})^{*}$ & $-1.12 \pm 0.23$ & $<.001$ & $-1.10 \pm 0.24$ & $<.001$ \\
\hline \multicolumn{5}{|l|}{ Procedure } \\
\hline Full sternotomy & $0.053 \pm 0.36$ & .9 & $0.41 \pm 0.52$ & .4 \\
\hline Mitral valve repair* & $-0.43 \pm 0.48$ & .4 & $-0.24 \pm 0.70$ & .7 \\
\hline \multicolumn{5}{|l|}{ Group } \\
\hline VAVR group $1^{*}$ & $-0.74 \pm 0.49$ & .13 & $-0.99 \pm 0.55$ & .07 \\
\hline VAVR group $2^{*}$ & $-1.16 \pm 0.42$ & .006 & $-1.42 \pm 0.49$ & .004 \\
\hline \multicolumn{5}{|l|}{ Propensity } \\
\hline Probability VAVR group 1 & - & - & $0.177 \pm 0.21$ & .4 \\
\hline Probability VAVR group 2 & - & - & $0.24 \pm 0.28$ & .4 \\
\hline Probability full sternotomy & - & - & $0.20 \pm 0.33$ & .5 \\
\hline
\end{tabular}

$S D$, Standard deviation; VAVR, vacuum-assisted venous return.

*Negative coefficient indicates decreased probability of blood product usage.

suction. The clinical benefit of VAVR is likely a combination of all effects. This may explain, in part, why incremental improvement was observed when transitioning from conventional gravity drainage to VAVR, without reduction of tubing length, and then to VAVR in its final iteration.

Reducing the need for transfusion of homologous blood products has been a goal of cardiac surgeons since the early 1980s. ${ }^{15-21}$ Identification of transfusion as a mode of disease transmission and an important morbidity has been a strong motivating factor for blood conservation. ${ }^{22,23}$ Modalities such as intraoperative autologous blood donation and retrograde autologous priming have been used with some success, ${ }^{24-26}$ and autotransfusion of shed mediastinal blood has been widely adopted. ${ }^{27}$

\section{VAVR}

Besides the clinical benefits of fewer transfusions, VAVR also permits the use of small-caliber venous cannulas, and the vacuum eliminates air locks that are common with conventional gravity drainage. This is especially apparent with dissection of the right atrium during reoperation and during emergency cannulation when the atrial purse-string suture is not in place. Nevertheless, LaPietra and colleagues ${ }^{28}$ have voiced concerns about the potential risk of introducing air emboli into the system. They demonstrated that air intentionally introduced into venous lines allowed some microbubbles $(<100 \mu \mathrm{m})$ to pass to the arterial cannula. Increasing vacuum (negative pressure) led to an increase in the number of microbubbles transmitted. How- 
ever, number of microbubbles (counts $\times \min ^{-1}$ ) and microbubble flow $\left(\mu \mathrm{L} \times \mathrm{min}^{-1}\right)$ were still low, so the clinical importance of their findings is unclear. No clinical complications of VAVR have been identified, but, as a precaution, entrained air should be kept to a minimum.

\section{Limitations}

Ideally, new, fully developed technology would be evaluated by randomized trial. However, introduction of technology often is iterative, leading in stages to a reengineered process. This was the case with VAVR.

Thus, the principal limitation of this study is its observational character during 2 sequential phases of VAVR implementation and refinement. However, 4 increasingly sophisticated forms of analysis lead us to believe that VAVR itself, not a confounding factor, was associated with the reduced blood product usage discovered. The first was simple unadjusted univariable analysis, which demonstrated incrementally lower blood usage in the VAVR groups. The second was multivariable analysis, used to assess VAVR effects in the presence of statistically and medically significant covariable adjustors. It supported the univariable result. The third was further multivariable adjustment by 2 propensity scores. ${ }^{29}$ Propensity score adjustment provides a unified way to adjust for group differences in analysis of outcomes in nonrandomized studies such as this. It cannot, however, correct for unmeasured variables that are not correlated highly with variables measured and accounted for in propensity models, and that may affect the end points considered. This adjustment was not statistically significant, supporting both univariable and multivariable analyses. The final form of analysis was propensity-matched-pairs analysis, which confirmed the finding that VAVR itself led to an important reduction in blood product usage, even though full sternotomy was associated with greater blood use and was more common in the gravity drainage group.

Another limitation is that the groups were sequential, rather than concurrent, because of iterative refinements of the technology. This temporal confounding can never be eliminated by propensity adjustment or matching.

The end points themselves posed analytic challenges with respect to distribution of the number of units of blood product used, requiring dichotomization with attendant loss of information content. They also posed a potential problem of bias, in that there was no strict protocol for transfusion; rather, transfusion was a clinical decision based on a general policy that transfusions were called for if the hematocrit value was $21 \%$ or less. Thus, we cannot exclude the possibility that blood conservation received a higher priority in the VAVR groups. Fang and colleagues ${ }^{30}$ have illustrated the relationship between increased operative mortality and hematocrit value during CPB of less than $14 \%$ (or $<17 \%$ in high-risk patients). Our transfusion trigger of $21 \%$ is higher than the danger limit shown by Fang and colleagues, but consistent with recommended guidelines. ${ }^{2}$

\section{Conclusions}

Revived as a technical improvement to facilitate minimally invasive surgery, VAVR also provides clinical benefits during and after CPB. We found that both intraoperative and postoperative hematocrit values were higher and few patients required blood product transfusion. No clinical disadvantages were identified. Given its technical facility and clinical utility, VAVR should be widely applied in cardiac surgery. At The Cleveland Clinic Foundation and now at many other institutions, it is standard for all patients undergoing cardiac surgery with use of CPB.

We thank Judy Holmes, RN, and Roberta Palumbo, RN, for study management, Perfusion Services for data collection, and Tess Knerik for editorial assistance.

\section{References}

1. Nadler SB, Hidalgo JU, Bloch T. Prediction of blood volume in normal human adults. Surgery. 1961;51:224-32.

2. Consensus conference. Perioperative red blood cell transfusion. JAMA. 1988;260:2700-3

3. Hosmer D, Lemeshow S. Applied logistic regression. New York: John Wiley; 1989.

4. Baskerville JC, Toogood JH. Guided regression modeling for prediction and exploration of structure with many explanatory variables. Technometrics. 1982;24:9-17.

5. Rosenbaum PR, Rubin DB. The central role of the propensity score in observational studies for causal effects. Biometrika. 1983;70:41-55.

6. Rubin DB. Estimating causal effects from large data sets using propensity scores. Ann Intern Med. 1997;127:757-63.

7. Kirklin JW, Barratt-Boyes BG. Cardiac surgery. 2nd ed. New York: Churchill Livingstone; 1993. p.76.

8. Jones RE, Donald DE, Swan HJ, Harshbarger HG, Kirklin JW, Wood EH. Apparatus of the Gibbon type for mechanical bypass of the heart and lungs: preliminary report. Mayo Clin Proc. 1955;30:105.

9. Jansen PG, te Velthuis H, Bulder ER, Paulus R, Scheltinga MR, Eijsman L, et al. Reduction in prime volume attenuates the hyperdynamic response after cardiopulmonary bypass. Ann Thorac Surg. 1995; 60:544-50

10. Westaby S, Pillai R, Parry A, O'Regan D, Giannopoulos N, Grebenik $\mathrm{K}$, et al. Does modern cardiac surgery require conventional intensive care? Eur J Cardiothorac Surg. 1993;7:313-8.

11. Westaby S. Invited commentary. Ann Thorac Surg. 1995;60:544-50.

12. Höhn L, Schweizer A, Licker M, Morel DR. Absence of beneficial effect of acute normovolemic hemodilution combined with aprotinin on allogeneic blood transfusion requirements in cardiac surgery. Anesthesiology. 2002;96:276-82.

13. Casati V, Speziali G, D'Alessandro C, Cianchi C, Antonietta Grasso $\mathrm{M}$, Spagnolo $\mathrm{S}$, et al. Intraoperative low-volume acute normovolemic hemodilution in adult open-heart surgery. Anesthesiology. 2002;97: 367-73.

14. Weiskopf RB. Efficacy of acute normovolemic hemodilution assessed as a function of fraction of blood volume lost. Anesthesiology. 2001; 94:439-46.

15. Jones JW, Rawitscher RE, McLean TR, Beall AC Jr, Thornby JI. Benefit from combining blood conservation measures in cardiac operations. Ann Thorac Surg. 1991;51:541-6.

16. Belisle S, Hardy JF. Hemorrhage and the use of blood products after adult cardiac operations: myths and realities. Ann Thorac Surg. 1996; 62:1908-17.

17. Scott WJ, Rode R, Castlemain B, Kessler R, Follis F, Pett SB, et al. Efficacy, complications, and cost of a comprehensive blood conserva- 
tion program for cardiac operations. J Thorac Cardiovasc Surg. 1992; 103:1001-7.

18. Goodnough LT, Despotis GJ, Hogue CW Jr, Ferguson TB Jr. On the need for improved transfusion indicators in cardiac surgery. Ann Thorac Surg. 1995;60:473-80.

19. Surgenor DM, Wallace EL, Churchill WH, Hao SH, Chapman RH, Collins JJ Jr. Red cell transfusions in coronary artery bypass surgery (DRGs 106 and 107). Transfusion. 1992;32:458-64.

20. Cosgrove DM, Thurer RL, Lytle BW, Gill CG, Peter M, Loop FD. Blood conservation during myocardial revascularization. Ann Thorac Surg. 1979;28:184-9.

21. Cosgrove DM, Loop FD, Lytle BW, Gill CC, Golding LR, Taylor PC, et al. Determinants of blood utilization during myocardial revascularization. Ann Thorac Surg. 1985;40:380-4.

22. Kaariainen L, Klemola E, Paloheimo J. Rise of cytomegalovirus antibodies in an infectious-mononucleosis-like syndrome after transfusion. $\mathrm{Br}$ Med J. 1966;5498:1270-2.

23. Aymard JD. Post-transfusion non-A, non-B hepatitis after cardiac surgery. Prospective analysis of donor blood anti-HBc antibody as a predictive indicator of the occurrence of non-A, non-B hepatitis in recipients. Vox Sang. 1986;51:236-8.

24. Helm RE, Klemperer JD, Rosengart TK, Gold JP, Peterson P, DeBois $\mathrm{W}$, et al. Intraoperative autologous blood donation preserves red cell mass but does not decrease postoperative bleeding. Ann Thorac Surg. 1996;62:1431-41.

25. Rosengart TK, DeBois W, O'Hara M, Helm R, Gomez M, Lang SJ, et al. Retrograde autologous priming for cardiopulmonary bypass: a safe and effective means of decreasing hemodilution and transfusion requirements. J Thorac Cardiovasc Surg. 1998;115:426-39.

26. Helm RE, Rosengart TK, Gomez M, Klemperer JD, DeBois WJ, Velasco F, et al. Comprehensive multimodality blood conservation: 100 consecutive CABG operations without transfusion. Ann Thorac Surg. 1998;65:125-36.

27. Schmidt H, Mortensen PE, Folsgaard SL, Jensen EA. Autotransfusion after coronary artery bypass grafting halves the number of patients needing blood transfusion. Ann Thorac Surg. 1996;61:1177-81.

28. Lapietra A, Grossi EA, Pua BB, Esposito RA, Galloway AC, Derivaux $\mathrm{CC}$, et al. Assisted venous drainage presents the risk of undetected air microembolism. J Thorac Cardiovasc Surg. 2000;120:856-62.

29. Blackstone EH. Comparing apples and oranges. J Thorac Cardiovasc Surg. 2002;123:8-15.

30. Fang WC, Helm RE, Krieger KH, Rosengart TK, DuBois WJ, Sason $\mathrm{C}$, et al. Impact of minimum hematocrit during cardiopulmonary bypass on mortality in patients undergoing coronary artery surgery. Circulation. . 1997;96(Suppl):II194-9.

31. Parsons LS. Reducing bias in a propensity score matched-pair sample using greedy matching techniques. Proceedings of the Twenty-sixth Annual SAS Users Group International Conference; 2001; Cary (NC): SAS Institute, Inc; 2001.

\section{Appendix 1}

\section{Variables Available for Analysis}

Demographics: Age, sex, and body surface area.

Hematology: Preoperative hematocrit, blood volume, and red blood cell volume.

Cardiac comorbidity: History of abnormal rhythm, history of atrial fibrillation, New York Heart Association functional class, and number of previous cardiac operations.

Noncardiac comorbidity: History of diabetes, history of stroke, and history of renal disease.

Procedure: Incision type (full sternotomy, ministernotomy, or thoracotomy), aortic valve replacement or repair, mitral valve replacement or repair, combined aortic and mitral procedure, and surgeon.

Operative: Length of time on cardiopulmonary bypass, first hematocrit value, and red blood cell mass on cardiopulmonary bypass.
APPENDIX TABLE 1. Probability of group membership (parsimonious models)

\begin{tabular}{lcc}
\hline Variable & Coefficient \pm SD & $P$ \\
\hline VAVR group 1 vs gravity drainage group & & \\
One or more previous & & \\
$\quad$ cardiac operations & $1.39 \pm 0.42$ & .002 \\
$\quad$ Ministernotomy & $3.3 \pm 0.46$ & $<.0001$ \\
Intercept & $-1.92 \pm 0.30$ & \\
Goodness of fit & $\mathrm{C}=.83$ & \\
VAVR group 2 vs gravity drainage group & & \\
$\quad$ Ministernotomy & $2.9 \pm 0.34$ & $<.0001$ \\
Intercept & $-0.89 \pm 0.177$ & \\
Goodness of fit & $\mathrm{C}=.79$ & \\
\hline
\end{tabular}

$S D$, Standard deviation; VAVR, vacuum-assisted venous return.

\section{Appendix 2}

\section{Development of Propensity Scores}

Main analysis. The steps described below were used in constructing the 2 group-related propensity scores used in data analyses. ${ }^{5,6,29}$

Parsimonious models for data subsets. To ensure mutually exclusive probabilities that would generate probabilities adding to 1.0, the data set was the first subset to include only the gravity drainage and VAVR 1 groups. Logistic regression was used to develop a parsimonious model for the probability of being in VAVR group 1 versus gravity drainage, based on patient and procedure variables (and specifically not on outcome variables). Logistic regression was repeated for the subsets of VAVR group 2 and gravity drainage (Appendix Table 1).

Propensity models for data subsets. Covariables from the parsimonious models were pooled and other covariables added that, although not statistically significant in either model, characterized major groups of variables that could give rise to selection bias. These include (1) age, (2) sex, (3) body surface area, (4) New York Heart Association functional class, (5) preoperative red blood cell volume, and (6) one or more previous cardiac surgeries (ministernotomy, mitral valve replacement, aortic valve replacement, and mitral valve repair). This complete set of covariables was incorporated into nonparsimonious logistic propensity models for the 2 subsets of data.

Calculation of propensity scores. Logit values for each of the 2 models, $\mathrm{z}_{1}(\mathrm{x})$ for VAVR group 1 and $\mathrm{z}_{2}(\mathrm{x})$ for VAVR group 2, were calculated for each patient in the entire data set. The 3 conditional probabilities for treatment groups given the chosen covariates were computed as: $\hat{P}(\mathrm{Y}=$ VAVR group $1 \mid \mathrm{x})=e^{\mathrm{z} 1(\mathrm{x})}$ $/\left(1+e^{\mathrm{z} 1(\mathrm{x})}+e^{\mathrm{z} 2(\mathrm{x})}\right), \hat{P}(\mathrm{Y}=\mathrm{VAVR}$ group $2 \mid \mathrm{x})=e^{\mathrm{z} 2(\mathrm{x})} /(1+$ $\left.e^{\mathrm{z} 1(\mathrm{x})}+\mathrm{e}^{\mathrm{z} 2(\mathrm{x})}\right)$, and $\hat{P}(\mathrm{Y}=$ gravity drainage $\mid \mathrm{x})=1 /\left(1+e^{\mathrm{z} 1(\mathrm{x})}\right.$ $\left.+e^{\mathrm{z} 2(\mathrm{x})}\right)$, where $\hat{P}$ is the probability of group membership and $e$ is base of the natural logarithms. These probabilities sum to 1 .

Verification of propensity score matching. The entire data set was sorted separately by each of the propensity scores. For each, 5 groups (quintiles) of similarly propensity-ranked patients were examined. Matching within quintiles was checked using $\chi^{2}$ or $t$ tests as appropriate for patient and procedure covariables. Quintiles were homogeneous with the exception of the first quintile in both cases. Because the patients in quintile one for the probability of being in VAVR group 1 were not the same as the patients in 
quintile one for the probability of being in VAVR group 2, no patient was omitted from analyses; rather, the propensity scores themselves were used as a mechanism of adjustment.

Use of propensity scores. Two of the 3 resulting conditional probabilities, $\hat{P}$ (Y $=$ VAVR group $1 \mathrm{x})$ and $\hat{P}(\mathrm{Y}=$ VAVR group $2 \mathrm{x}$ ), were used as covariates in multivariable analyses of outcome.

\section{Confirmation Analysis}

Using logistic regression as above, both a parsimonious and a propensity model were developed for full sternotomy versus minimally invasive approach. Patients receiving a full sternot- omy were older $(P=.06)$, more symptomatic $(P=.03)$, more likely to have had a stroke $(P=.04)$ or renal failure $(P=.04)$, and less likely to have undergone mitral valve repair $(P<$ $.001)$.

A propensity score was calculated for each patient. By the technique of greedy matching, it was used to match one-to-one 98 of the 120 patients having full sternotomy with 98 of the 176 patients having the minimally invasive approach. ${ }^{31}$ These 196 propensity-matched paired patients were analyzed exactly as the main group was; however, propensity adjustment was with respect not only to group but also to surgical approach.

\section{UN THE MOVE?}

Don't miss a single issue of the journal! To ensure prompt service when you change your address, please photocopy and complete the form below.

Please send your change of address notification at least six weeks before your move to ensure continued service. We regret we cannot guarantee replacement of issues missed due to late notification.

\section{JOURNAL TITLE:}

Fill in the title of the journal here.

\section{OLD ADDRESS:}

Affix the address label from a recent issue of the journal here.

\section{NEW ADDRESS:}

Clearly print your new address here.

Name

Address

City/State/ZIP

\section{COPY AND MAIL THIS FORM TO:}

Mosby

Subscription Customer Service

6277 Sea Harbor Dr

Orlando, FL 32887
OR FAX TO:

407-363-9661

NM Mosby
OR PHONE:

800-654-2452

Outside the U.S., call

407-345-4000 